\title{
DEVELOPMENT AND EVALUATION OF CIPROFLOXACIN HYDROCHLORIDE LOADED OCULAR INSERT BY USING “PLANTAGO OVATA” AS NATURAL POLYMER
}

\author{
AYUSHI CHOURASIA*, SHIKHA AGRAWAL \\ Department of Pharmaceutics, Swami Vivekanand College of Pharmacy, Indore 452020, Madhya Pradesh, India \\ Email: ayushi.chourasia4@gmail.com
}

Received: 21 Apr 2018, Revised and Accepted: 10 Jun 2018

\begin{abstract}
Objective: The present work focus in the direction of "Development and evaluation of Ciprofloxacin Hydrochloride loaded ocular insert by using "plantago ovata" as natural polymer". The current work was carried out to evaluate the control release profile of ocular insert. Natural polymer in ocular insert was used for studying the long acting property. Natural polymer is also used to enhance the bioavailability of drug and reduce toxicity. It is also used to increase the duration of action of drug for prolongs action and gives better in vitro performance as compare than to the conventional ocular formulation.
\end{abstract}

Methods: Solvent casting method was used in the formulation of Ciprofloxacin Hydrochloride loaded ocular inserts. Different ocular insert formulations of varying polymer concentration were prepared. Ocular insert formulation $\mathrm{H}-1$ to $\mathrm{H}-3$ was prepared by using different concentration of HPMC and formulation P-1 to P-4 was prepared by using different concentration of Plantago Ovata.

Results: The ocular inserts formulation was within the acceptable limits. All the pre formulation parameters of polymers such as derived properties, compressibility index, Hausner's ratio, viscosity, melting point, swelling ratio, loss on drying, PH of mucilage solution and pre formulation of active pharmaceutical ingredient such as estimation of drug by using UV spectroscopy, determination of melting point, solubility, partition coefficient and FTIR for compatibility study of drug and excipient were evaluation. FTIR analysis also confirmed no drug-excipient interaction.

Conclusion: Prepared inserts in the present study were semitransparent. The mixing of the drug in to the polymer is uniform, due to this; the drug content of all formulation is good. Formulation P4 was selected because it showed better release profile, drug content and other physicochemical properties than other formulated batch when compare. All the prepared inserts showed in vitro drug release for the period of $4 \mathrm{~h}$ as compare to the marketed formulation. An in vitro drug release study revealed that ocular formulation gives a prolong action. The formulation was found to be long acting.

Keywords: Ciprofloxacin Hydrochloride, HPMC, Plantago Ovata, Occular insert

(C) 2018 The Authors. Published by Innovare Academic Sciences Pvt Ltd. This is an open access article under the CC BY license (http://creativecommons.org/licenses/by/4.0/] DOI: http://dx.doi.org/10.22159/ijcpr.2018v10i4.28474

\section{INTRODUCTION}

The present work focus in the direction of "Development and evaluation of Ciprofloxacin hydrochloride loaded ocular insert by using "Plantago ovata" as natural polymer". Ocular insert were developed to enhance the activity and increase the availability of drug in ocular region for prolong duration of action and their long time release property. Solvent casting method was used in the fabrication of the formulation.

A basic concept in ophthalmic research and development is that the therapeutic efficacy of an ophthalmic drug can be greatly improved by prolonging its contact with the corneal surface. Ophthalmic inserts have many advantages over conventional dosage form like increased ocular residence time, possibility of releasing drugs at a slow and constant rate, accurate dosing, exclusion of preservatives and increased shelf-life. It also ensures better patient compliance due to lower frequency of administration and lower incidence of side effects [1].

Soluble ocular inserts are slowly soluble into the ocular region so that they do not require to be removed from their application site. The drug release from soluble ocular inserts promote continuous release rate. This is due to diffusion mechanism and gel layer formation outside the core of the insert [2-3].

Ciprofloxacin hydrochloride is the hydrochloride salt form of ciprofloxacin. It is second generation fluoroquinolone related to anti bacterial activities that usually result in the death of bacteria. This broad spectrum activity allow the use of Ciprofloxacin Hydrochloride in a variety of infections including those affecting the respiratory tract, urinary tract, skin, soft tissues and the eyes. Studies in literature showed that fluoroquinolones antibiotic group was more effective in the treatment of ocular infections than some other broad spectrum antibiotics [4].

The main aim of this study is to reducing the side effect which is produce by the conventional dosage form and the synthetic polymers used in the formulation by using Natural Polymer. Plantago ovata is a natural herb used as drug for the treatment of various diseases and it mostly used as pharmaceutical excipients like binder, gelling in nature and it, also used as enteric coated material, tablet disintegrator and sustain release drug formulation [5].

\section{MATERIALS AND METHODS}

Material

Ciprofloxacin hydrochloride was kindly gifted by Cipla pharmaceuticals (Pithampur). Seeds of plantago ovate was procured by local market (Indore), HPMC was purchased from Lobo Chemie private Ltd (Mumbai, India), Glycerin by Merck (Mumbai, India).

Methods

\section{Isolation of mucilage}

The dried seeds of plantago ovate were soaked in distilled water for $24 \mathrm{~h}$. After this period the mixture of plantago ovata and water was boiled for $1 \mathrm{~h}$ and keep a side for $2 \mathrm{~h}$. The viscous fluid was filtered through the muslin cloth, squeezed out and separating the mucilage from the seeds. The collected mucilage precipitated by the using of double amount of ethanol. After this the collected mucilage was 
dried in the oven at 50-55 ${ }^{\circ} \mathrm{c}$. Dried mucilage was scraped and powdered by the using pestle-mortar and Sieved by using mesh no.60 and store in desiccators [6-8].

\section{Preformulation studies}

Pre-formulation studies of polymer involves the application of physicochemical parameters like derived property, compressibility index, hausner's ratio, melting point, swelling ratio, loss on drying, $\mathrm{PH}$ of the mucilage solution [9-12]. Whereas preformulation of drug comprises of spectrophotometric estimation, solubility, melting point, partition coefficient and drug Excipient compatibility studies.

\section{Spectrophotometric estimation of drug}

For the estimation of drug, UV visible spectroscopic method was adopted [13]

Ciprofloxacin hydrochloride solution of about 200 ppm was accurately prepared in water. This solution was scanned in the 200-400 nm UV regions. The wavelength maximum was observed and wavelength maximum obtained was adopted for absorbance measurement.

For standard stock solution accurately weighed Ciprofloxacin hydrochloride $(100 \mathrm{mg}$ ) was transferred to a volumetric flask and sufficient water was added to produce $100 \mathrm{ml}$ (this is stock solution). From the above stock solution $10 \mathrm{ml}$ was withdrawn and transferred to a volumetric flask and sufficient water was added to produce $100 \mathrm{ml}$ (this is standard stock solution). From the above standard stock solution different aliquots were prepared in the concentration range from 1-10 ug/ml. Absorbance of aliquots were measure on UV-VIS spectrophotometer at $\lambda$ max $318 \mathrm{~nm}$ using water as blank solution [14]. Graphical representation of standard curve of Ciprofloxacin Hydrochloride was shown in fig. 1.

\section{Determination of melting point}

Capillary method was used for the determination of melting point [15].

\section{Solubility determination}

Different solvents were used for the solubility determination of drug such as water, methanol, ethanol, simulated tear fluid $\mathrm{pH} 7.4$ and acetone.

\section{Partition co-efficient (shaking flask method)}

Ten mg of drug was added in $100 \mathrm{ml}$ of volumetric flask containing 50:50 ml ratio of n-octanol: water and the mixture was allow to be shaking by mechanical shaker for $24 \mathrm{~h}$. After this allow the solution for separation of two phases for 1 hour. The mixture was divided in two immiscible phase, both phases were separated (by separating funnel) and the absorbance of both phases was taken and concentration was calculated of each phases.

$$
\text { Partition Co efficient }=\frac{\text { Drug concentration in octanol }}{\text { Drug concentration in Water }}
$$

\section{Drug-excipients compatibility studies}

Chemical interaction between the pure drug and the other excipients which were used in the formulation was detected by the use of Infrared spectroscopic method. In this the FTIR spectra of pure drug and physical mixture (drug and polymer mixture) were taken as in the ranging from $4000-650 \mathrm{~cm}-1$. The drug, and 1:1 ratio of polymer and plasticizer (each $10 \mathrm{mg}$ ) was mixed in $400 \mathrm{mg}$ of $\mathrm{Kbr}$. Compressed this mixture about $100 \mathrm{mg}$ by the using of a hydraulic press at 10 tones pressure to prepared a pellet. Pellets of the physical mixture were scanned in the ranging from of 4000-400 cm1in IR spectrophotometer. Collecting the IR spectra of physical mixtures and compared with drug to detect any visible or invisible of peaks [16].

\section{Formulation of ocular inserts}

Preparation of ocular inserts was done by using solvent casting method-in this method accurately weighed the polymer (either plantago ovata mucilage or HPMC) and dissolved in distilled water and formulate a clear solution. In another beaker drug was dissolved in water $(2 \mathrm{ml})$ under mild agitation. And then the drug solution was added to polymeric mixture with gentle agitation. Then glycerin was added to the above mixture. This mixture was transferred into a glass mould and dried in a room temperature for $3 \mathrm{~d}(72 \mathrm{~h})$. After complete drying polymer films containing drug were formed. The dried films of drug were cut to circular discs (ocular inserts) of diameter $1.0 \mathrm{~cm}$, and stored in the desiccators until further studies [17]. Optimization data was shown in table 1.

Table 1: Optimization data of ciprofloxacin hydrochloride ocular insert

\begin{tabular}{|c|c|c|c|c|c|}
\hline Formulation & $\begin{array}{l}\text { Ciprofloxacin } \\
\text { hydrochloride }\end{array}$ & $\begin{array}{l}\text { Mucilage plantago ovate } \\
\text { (polymer) }\end{array}$ & $\begin{array}{l}\text { HPMC } \\
\text { (polymer) }\end{array}$ & Plasticizer (glycerin) & Solvent (distill. water) \\
\hline P1 & $30 \mathrm{mg}$ & $50 \mathrm{mg}$ & - & $8 \mathrm{mg}$ & $10 \mathrm{ml}$ \\
\hline $\mathrm{P} 2$ & $30 \mathrm{mg}$ & $100 \mathrm{mg}$ & - & $8 \mathrm{mg}$ & $10 \mathrm{ml}$ \\
\hline P3 & $30 \mathrm{mg}$ & $200 \mathrm{mg}$ & - & $8 \mathrm{mg}$ & $10 \mathrm{ml}$ \\
\hline P4 & $30 \mathrm{mg}$ & $300 \mathrm{mg}$ & - & $8 \mathrm{mg}$ & $10 \mathrm{ml}$ \\
\hline H1 & $30 \mathrm{mg}$ & - & $200 \mathrm{mg}$ & $8 \mathrm{mg}$ & $10 \mathrm{ml}$ \\
\hline $\mathrm{H} 2$ & $30 \mathrm{mg}$ & - & $300 \mathrm{mg}$ & $8 \mathrm{mg}$ & $10 \mathrm{ml}$ \\
\hline $\mathrm{H} 3$ & $30 \mathrm{mg}$ & - & $400 \mathrm{mg}$ & $8 \mathrm{mg}$ & $10 \mathrm{ml}$ \\
\hline
\end{tabular}

\section{Evaluation of ophthalmic inserts}

\section{Physical appearance}

It was done by visual inspection. In this following property was studied like the color, clarity, smoothness and nature of the drug [18].

\section{Surface PH}

Surface $\mathrm{PH}$ of the ocular insert was determined by the using of $\mathrm{PH}$ indicator paper after allowing the inserts to swell on $2 \%$ agar solution for $5 \mathrm{~h}$. The surface $\mathrm{PH}$ was measured by means of a $\mathrm{PH}$ paper which was placed on the surface of swollen film of insert [1820].

\section{Swelling index}

Swelling studies of prepare ocular insert was determined in the STF 7.4 PH. In this three inserts were taken and weighed accurately and place in the test tube individually containing $4 \mathrm{ml}$ of STF 7.4 PH. At specific time intervals the inserts was removed and the excess water present on their surface was removed using a blotting paper and reweighed the ocular insert. The procedure was repeated till there was no increase in the weight of ocular inserts. Swelling index of ocular insert was then calculated.

\section{Thickness}

Thickness of the ocular insert was carried out by using vernier callipers. Thickness of insert was measured at the five different point such as centre and four corners and the average was determined by the using of vernier callipers [21-22].

\section{Uniformity of weight}

This was carried out by the using digital electronic balance. In this evaluation five insert were taken from each batch and weighted individually and variation of weight measured by digital electronic balance [23]. 


\section{Folding endurance}

The polymeric ocular films flexibility was determined in terms of folding endurance. A small strip of ocular film was cut evenly and folded separately at the same place until it broke. The film could be folded at the same place with access number of times without break give the folding endurance [24].

\section{Moisture absorption}

The percentage moisture absorption test was measured out to check the integrity and of the ocular film. Individually weighed the ocular films and was placed in a desiccator having $100 \mathrm{ml}$ of saturated salt solution of sodium chloride ( $\sim 75 \%$ humidity). After three days ocular films was taken out and reweighed; the percentage moisture absorption was calculated by using following formula.

$$
\text { Moisture absorption (\%) }=\frac{\text { Final weight }- \text { Initial weight }}{\text { Initial weight }} \times 100
$$

\section{Percentage moisture loss}

The percentage moisture loss test was measured out to check the integrity of the ocular film at the dry condition. Individually weighed the ocular films and placed in desiccators having $100 \mathrm{ml}$ of anhydrous calcium chloride. After three ocular films was taken out and reweighed; the percentage moisture loss was calculated by using following formula.

$$
\text { Moisture loss }(\%)=\frac{\text { Initial weight }- \text { Final weight }}{\text { Initial weight }} \times 100
$$

\section{Drug content uniformity}

Ocular inserts from each batch were dissolved in the $100 \mathrm{ml}$ volumetric flasks containing simulated tear fluid PH 7.4 and solution was filtered. Then, mishearing the absorbance in a UV spectrophotometer at $278 \mathrm{~nm}$ after suitable dilution with STF PH 7.4 against a blank insert prepared using a free drug.

\section{In vitro drug release study}

In vitro drug release studies were performed in vertical Franz diffusion cell. STF pH 7.4 was placed in the receiver compartment. An ocular insert of Ciprofloxacin Hydrochloride was placed in the donor compartment. Egg membrane was used to separate the donor and receiver compartments. The diffusion cells were maintained at $\left(37 \pm 0.5^{\circ} \mathrm{C}\right)$ with stirring at $600 \mathrm{rpm}$ throughout the experiment. At fixed time intervals, $5 \mathrm{ml}$ of the sample was withdrawn from receiver compartment though side tube and analyzed by UV-Visible spectrophotometer at $278 \mathrm{~nm}$ [25].

\section{Sterility testing}

Sterility testing for the ophthalmic preparation is one of the most important requirements. The sterility testing for ocular insert intended for detecting the presence of viable microorganisms. According to this study if the microorganisms are placed in the culture media and providing nutritive material, water, kept at a favorable temperature, the microorganisms will grow up, and turbidity will form because of the presence of microorganism in a clear medium. In this study, two media were used namely, alternate thioglycolate medium (FTGM) and soya bean-casein digest medium (SCDM) to identify the presence/absence bacteria and fungi, in the prepared sterilized ocular inserts [26-27].

\section{RESULTS AND DISCUSSION}

\section{Characterization of mucilage of plantgo ovate}

The physiochemical properties of dried powder of mucilage of plantago ovata were given in table 2. According to IP, angle of repose shows excellent flow of powder which can be concluded that the mucilage having a good flow properties which is suitable for a formulation.

Table 2: Characterization table of mucilage of plantago ovata

\begin{tabular}{lll}
\hline S. No. & Properties & Mean \\
\hline 1 & Angle of repose $(\mathrm{g} / \mathrm{ml})$ & 26.27 \\
2 & Bulk density $(\mathrm{g} / \mathrm{ml})$ & 0.32 \\
3 & Tapped density & 0.51 \\
4 & Carr's index & 37.52 \\
5 & Hausner's ratio & 1.59 \\
\hline
\end{tabular}

\section{Melting point}

Melting point plantago Ovata mucilage is found to be $72-80^{\circ} \mathrm{C}$ which is suitable for the formulation.

\section{Swelling ratio}

The swelling ratio of mucilage, determined in distilled water, is found to be 3.0. There is a significant change in swelling by the end of the study, which indicated that the mucilage had excellent swelling properties.

\section{Loss on drying}

The weight loss on heating justified that the amount of moisture is available in the material to interact with the other material. For dried mucilage, the loss on drying was found to be $20.33 \%$.

\section{PH of the mucilage solution}

$\mathrm{PH}$ of the $1 \%$ solution of the mucilage of plantago ovata was detected by the digital PH meter and the sample PH was found to be 6.9.

\section{Viscosity}

The viscosity of the mucilage solutions was done by the Brookfield viscometer, the result shown in table 3 which indicate that the mucilage viscosity is suitable for the formulations.

\section{Estimation of drug \\ Identification of drug}

The identification of drug is done by UV Spectrophotometric method using distilled water. Fig. 1 show the standard curve of Ciprofloxacin Hydrochloride in distilled water.

\section{Determination of melting point}

The melting point of the ciprofloxacin hydrochloride was found to be $310-320^{\circ} \mathrm{C}$ which was according to the standards.

\section{Solubility determination}

Solubility of ciprofloxacin hydrochloride in various solvents were given in table 4, which shows that the drug is soluble in STF PH 7.4 which is good for ophthalmic preparation.

Table 3: Viscosity of mucilage solution

\begin{tabular}{lll}
\hline S. No. & Solutions & Obtaining viscosity \\
\hline 1 & $0.1 \%$ & $1.48 \mathrm{cps}$ \\
2 & $0.2 \%$ & $2.98 \mathrm{cps}$ \\
3 & $0.3 \%$ & $5.74 \mathrm{cps}$ \\
4 & $0.4 \%$ & $8.25 \mathrm{cps}$ \\
5 & $0.5 \%$ & $9.30 \mathrm{cps}$ \\
\hline
\end{tabular}




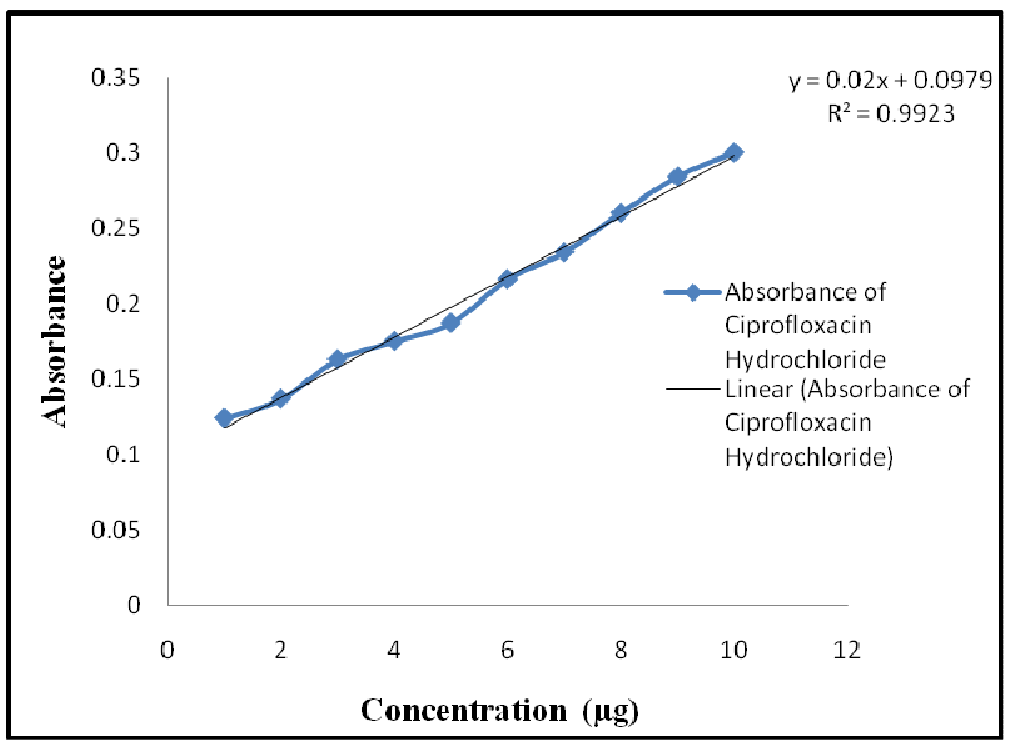

Fig. 1: UV estimation of ciprofloxacin hydrochloride in distilled water $(\lambda \max =318 \mathrm{~nm})$

Table 4: Solubility of drug in various solvents

\begin{tabular}{lll}
\hline S. No. & Solubility & Solvent \\
\hline 1 & Distilled water & $* * * * *$ \\
2 & STF 7.4 PH & $* * * *$ \\
3 & Methanol & $* * *$ \\
4 & Ethanol & $* *$ \\
5 & Acetone & $*$ \\
\hline
\end{tabular}

*insoluble, ${ }^{* *}$ very slightly soluble, ${ }^{* * *}$ slightly soluble, ${ }^{* * * *}$ soluble, ${ }^{* * * * *}$ freely soluble, $\left({ }^{*}\right)$ sign indicates the solubility

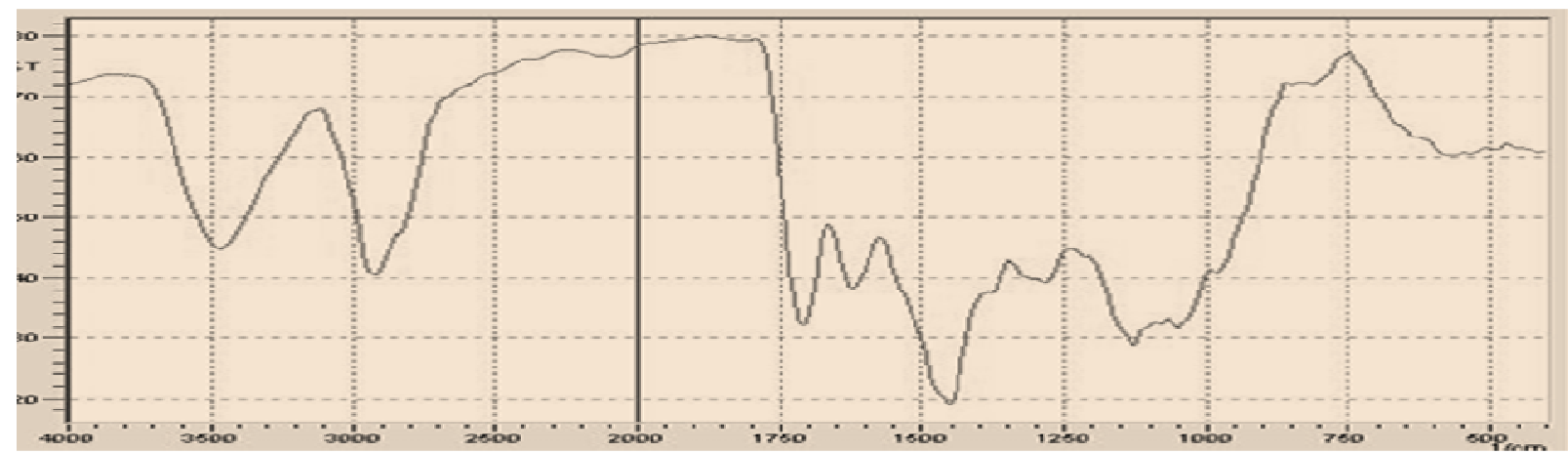

Fig. 2: FTIR of ciprofloxacin hydrochloride

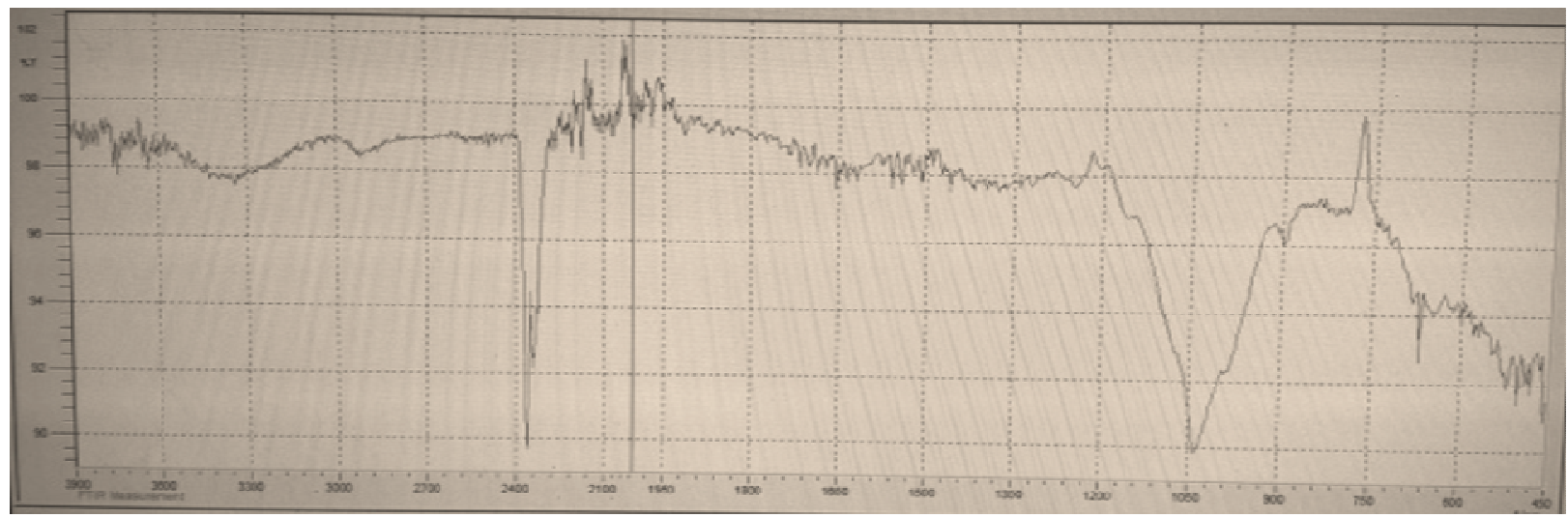

Fig. 3: FTIR of plantago ovate 


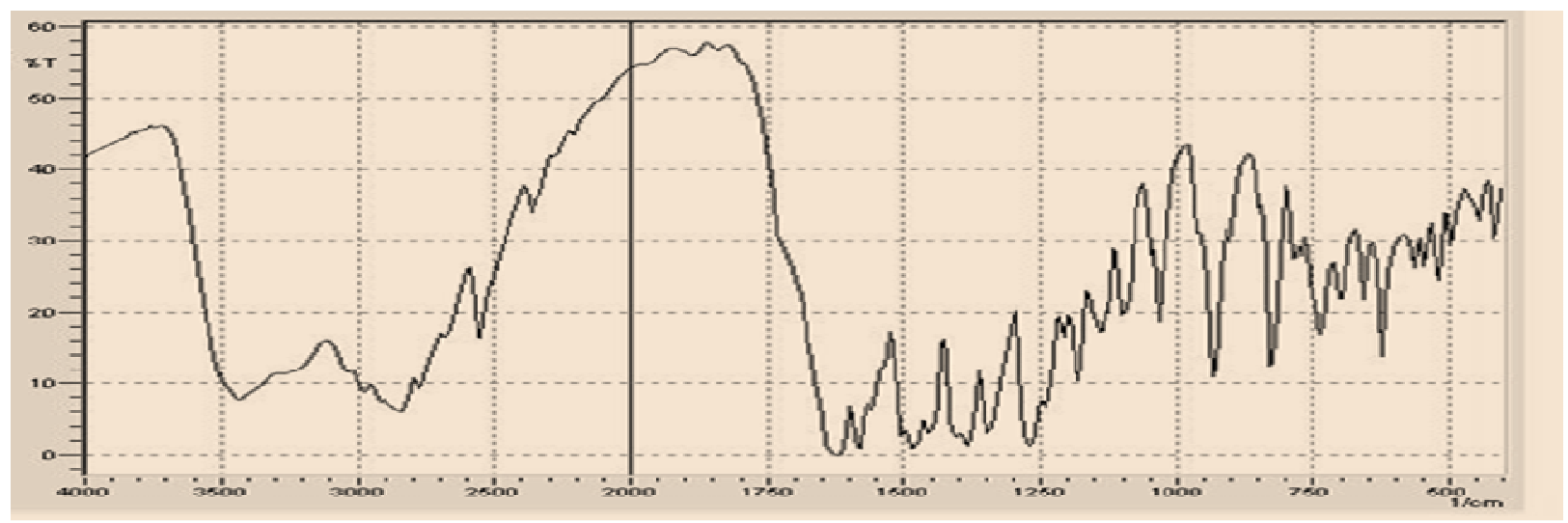

Fig. 4: FTIR of drug and polymer (plantago ovate) mixture)

\section{Drug-excipients compatibility studies by FTIR method}

In the FTIR spectra of the drug and polymer, the peak from 3500 to $3400 \mathrm{~cm}^{-1}$ was assigned to polymeric and hydrogen bonding while the band between 3000 and $2600 \mathrm{~cm}^{-1}$ represented the stretching vibration i.e., strong intermolecular hydrogen bonding. The band from 1650 to $1600 \mathrm{~cm}^{-1}$ was assigned to carbonyl stretching vibration. The band from 1400-1350 $\mathrm{cm}^{-1}$ represents esters and symmetric bending of methoxy groups. The peak between 1100 and $1000 \mathrm{~cm}^{-1}$ represented drug and polymer shows no major interactions.

\section{Partition co-efficient}

The partition coefficient value of ciprofloxacin hydrochloride is found to be 0.99 . The $\log \mathrm{k}$ values of ciprofloxacin hydrochloride show that the drug should Processes sufficient lipophilicity, which requirements is essential for the formulating it into an ocular insert

\section{Physical properties}

The result of physical properties like thickness, uniformity of weight and folding endurance were given in table 5.

\section{Surface PH}

The surface PH of the formulated ciprofloxacin hydrochloride ocular inserts by natural polymer is found between 6.0 to 7.5 indicated the good for ocular formulation

\section{Swelling study}

Swelling percentage of the prepared ciprofloxacin hydrochloride ocular insert by natural polymer is found between 11.1 to $86.6 \%$ and by HPMC polymer is found to be 3.12 to $60 \%$. All the design batches of ocular inserts have a high swelling index Graphical representation of swelling profile is given in fig. 5 and 6.

Table 5: Physical properties of prepared ocular film of ciprofloxacin hydrochloride

\begin{tabular}{lllll}
\hline S. No. & Batch & Thickness $(\mathbf{m m})$ & Uniformity of weight (gms) & Folding endurance (no. of flods) \\
\hline 1 & P1 & 0.38 & 0.0148 & 50.66 \\
2 & P2 & 0.49 & 0.018 & 57.63 \\
3 & P3 & 0.57 & 0.0174 & 60.23 \\
4 & P4 & 0.65 & 0.021 & 65.32 \\
5 & H1 & 0.14 & 0.0164 & 56.63 \\
6 & H2 & 0.10 & 0.0112 & 51.63 \\
7 & H3 & 0.20 & 0.0114 & 63.06 \\
\hline
\end{tabular}

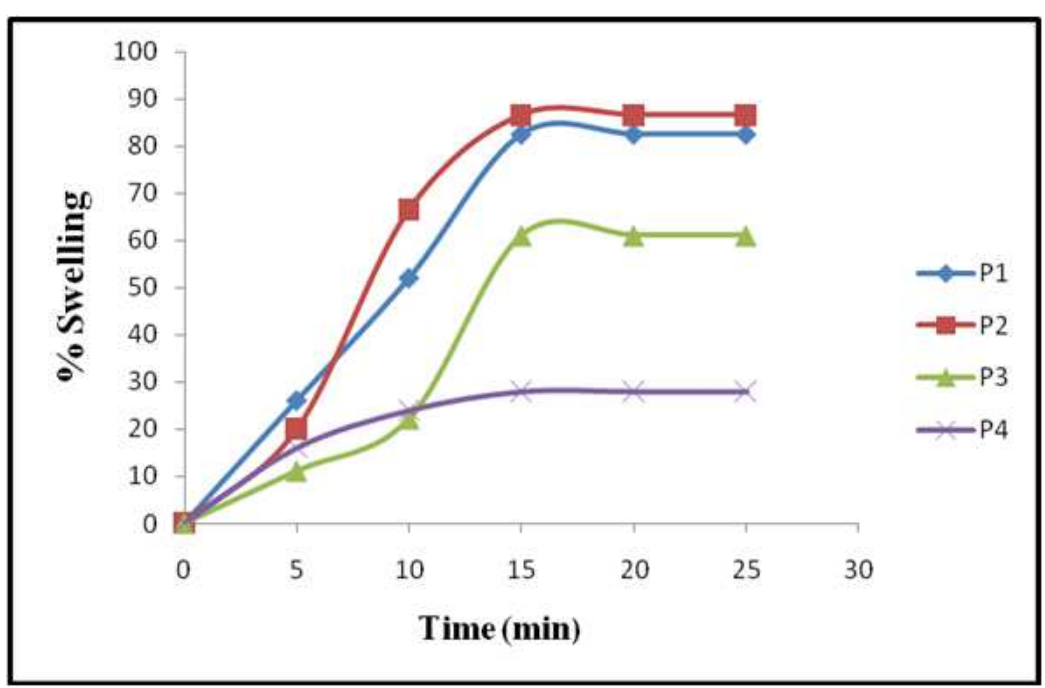

Fig. 5: Swelling profile of ciprofloxacin hydrochloride ocular insert containing natural polymer 


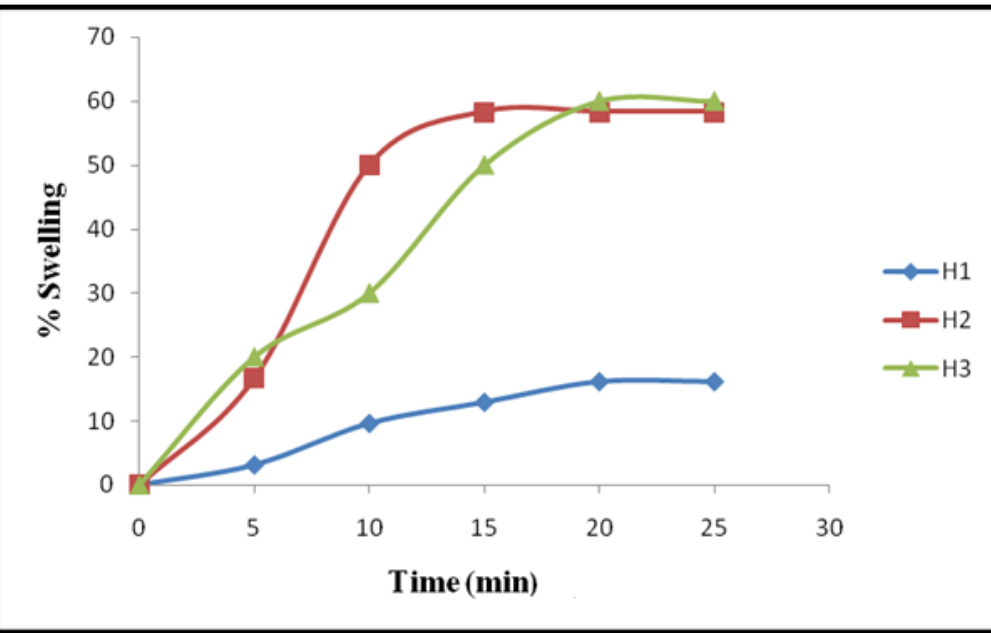

Fig. 6: Swelling profile of ciprofloxacin hydrochloride ocular insert containing HPMC

\section{Moisture absorption/loss}

The study found that prepared ocular insert shows high moisture absorption and insert absorbs large amount of moisture thus formulation were not stored for long time. The percent moisture absorbed and loss result is given in table 6 and graphically presented in fig. 7.

Table 6: \% moisture absorption and loss

\begin{tabular}{lll}
\hline Batch & \% moisture absorption & \% moisture loss \\
\hline P1 & 25 & 10 \\
P2 & 21.73 & 14.28 \\
P3 & 6.6 & 6.25 \\
P4 & 12.90 & 4.5 \\
H1 & 63.63 & 16.66 \\
H2 & 12.5 & 12.5 \\
H3 & 21.42 & 14.28 \\
\hline
\end{tabular}

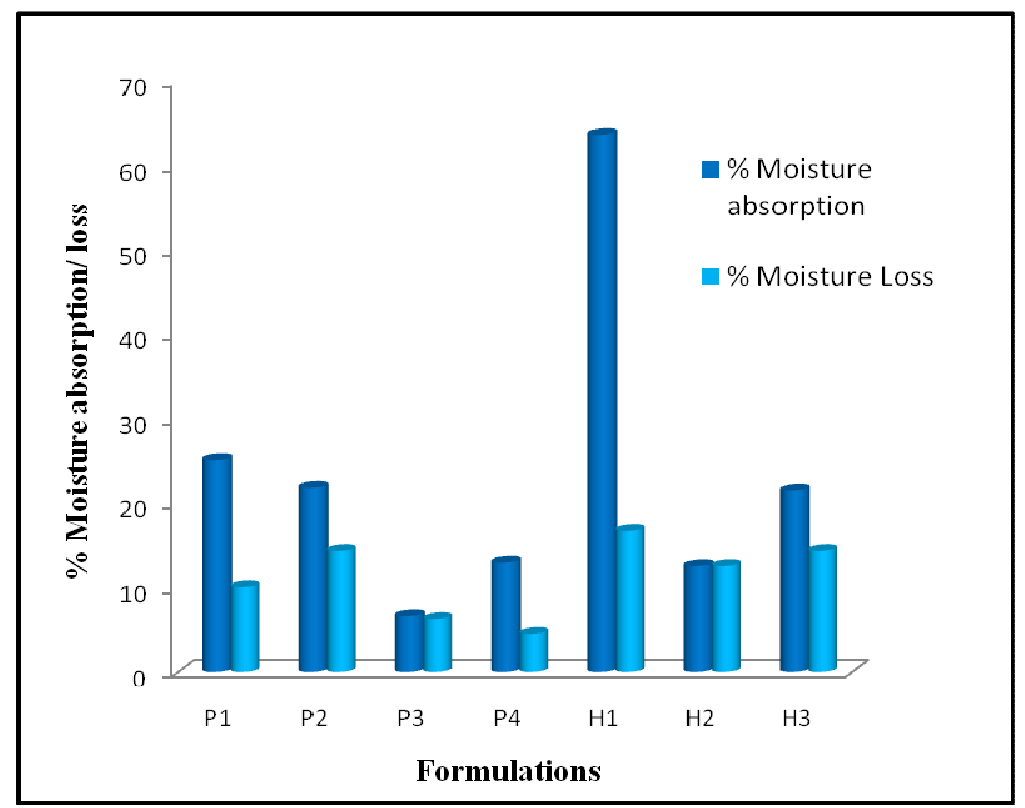

Fig. 7: Graphical representation of \% moisture contain and loss of ciprofloxacin hydrochloride ocular insert contain natural polymer (P1P4) and HPMC (H1-H3)

\section{Drug contents}

The test for content uniformity of drug in all batches of ocular insert contain natural polymer and HPMC is carried out to ascertain that the drug is uniformly distributed in the formulation. The amount of drug present in the prepare formulation containing natural polymer is found to be 91.38 to 98.19 and HPMC is found to be 92 to 94.19 which is presented in table 7 and graphically shown in fig. 8 and 9 . This study shows the good uniformity in drug content in ocular insert. 
Table 7: \% drug content

\begin{tabular}{lll}
\hline S. No. & Batch & \% drug content \\
\hline 1 & P1 & 91.21 \\
2 & P2 & 90.18 \\
3 & P3 & 91.38 \\
4 & P4 & 98.19 \\
5 & H1 & 92 \\
6 & H2 & 94.19 \\
7 & H3 & 93.37 \\
\hline
\end{tabular}

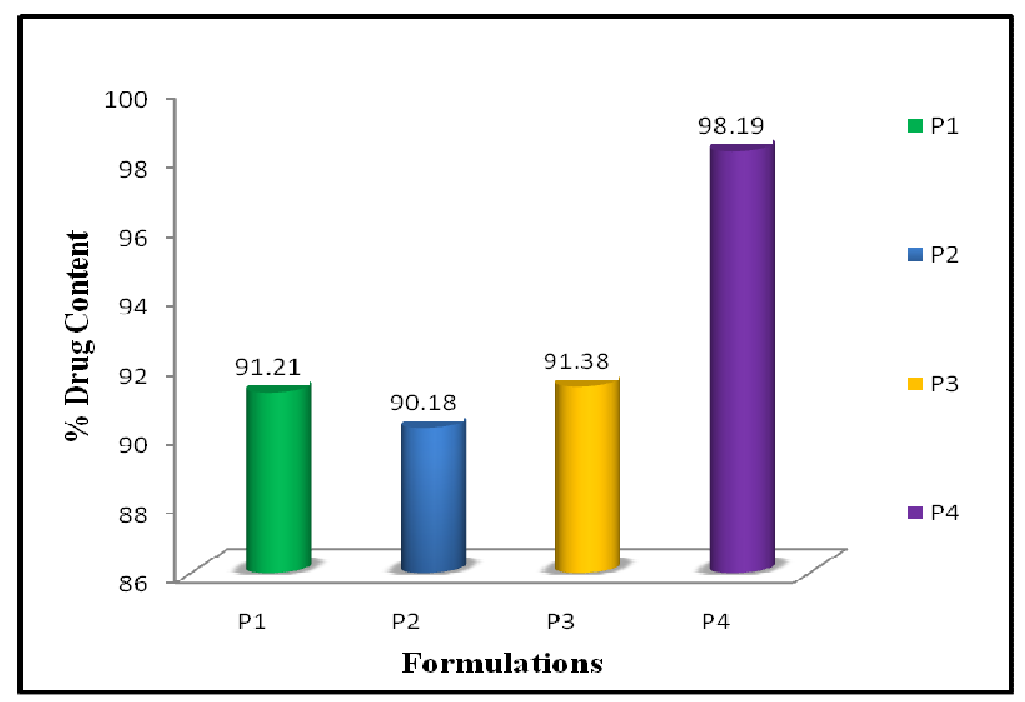

Fig. 8: \% Drug content of ocular insert contain drug with natural polymer

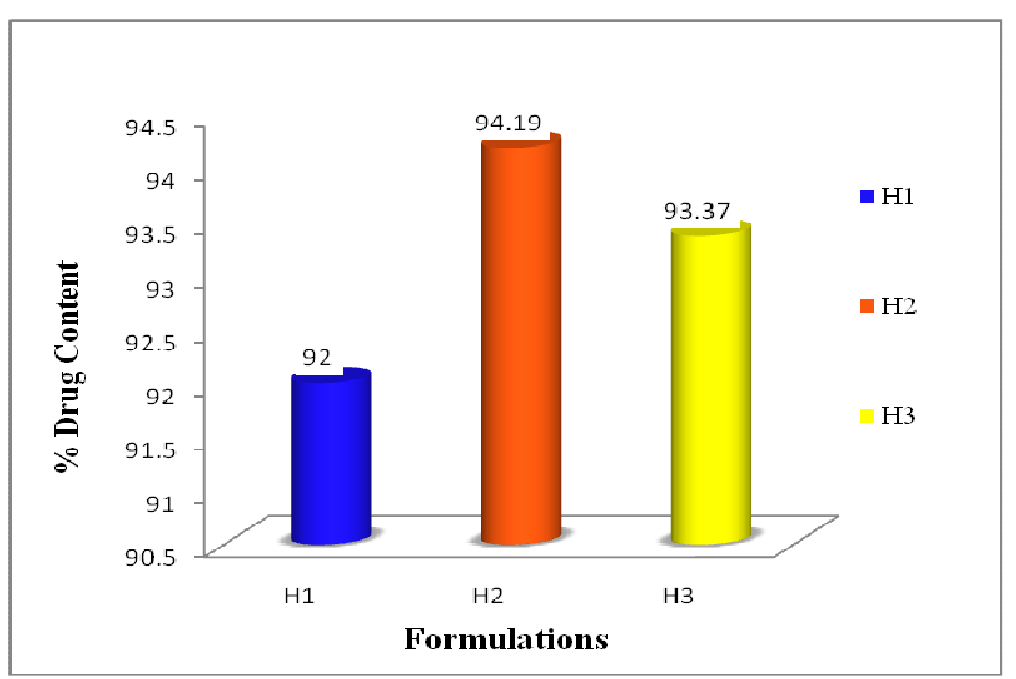

Fig. 9: \% drug content of ciprofloxacin hydrochloride ocular insert containing HPMC

\section{In vitro studies}

In vitro studies were performed to compare the release rate of the drug from ocular insert containing HPMC and natural polymer (Plantago ovata) which is coded as $\mathrm{H} 1$ to $\mathrm{H} 3$ and P1 to P4. Cumulative percent drug release of ciprofloxacin hydrochloride loaded ocular insert is investigated for $4 \mathrm{hr}$. As results indicated that the \% drug release for ocular insert P4 and H2 is 99.48 and 98.25 at the end of $4 \mathrm{~h}$ which was shown in table 8 and graphically presented in fig. 10 and 11.

\section{Comparative studies}

Compared the selected batches of the formulation containing HPMC and Natural polymer plantago ovata according to their following evaluation studies such as folding endurance, \% drug content, \%swelling profile and In vitro release studies. The result is shown in table 9-10 and in fig. 12-13.

\section{In vitro release studies}

Comparison study of In vitro release shows that formulation batch P4 (of natural polymer) showed good release profile as compare to the formulation batch containing HPMC.

\section{Sterility testing}

The sterility testing of prepared ocular insert P4 is performed for bacteria and fungi by using FTGM (fluid thioglycolate medium) and SCDM (Soyabean casin digest medium) 


\section{Test for bacteria}

In this study there was no sign of growth found in the 'test' and 'negative control' tubes containing ocular insert and there was macroscopic evidence of microbial growth in 'positive control' tube. The results found that the prepared ocular insert P4 tested for bacterial growths were passed the test for sterility.

Table 8: \% drug release (in vitro studies) of ocular inserts

\begin{tabular}{|c|c|c|c|c|c|c|c|c|}
\hline \multirow[t]{2}{*}{ S. No. } & \multirow[t]{2}{*}{ Time (h) } & \multicolumn{7}{|c|}{$\%$ drug release of formulations } \\
\hline & & P1 & $\mathbf{P 2}$ & P3 & P4 & H1 & H2 & H3 \\
\hline 1 & 0 & 0.45 & 0.21 & 0.17 & 0.11 & 0.89 & 1.56 & 1.71 \\
\hline 2 & $1 / 2$ & 2.11 & 1.41 & 8.46 & 7.52 & 2.46 & 10.72 & 9.73 \\
\hline 3 & 1 & 14.56 & 7.69 & 20.02 & 25.68 & 15.45 & 28.96 & 20.90 \\
\hline 4 & $1 \frac{1}{2}$ & 35.65 & 19.87 & 32.94 & 38.82 & 27.09 & 50.49 & 47.65 \\
\hline 5 & 2 & 51.42 & 26.67 & 46.85 & 52.03 & 31.91 & 62.92 & 55.98 \\
\hline 6 & $21 / 2$ & 78.90 & 38.27 & 72.44 & 69.55 & 49.07 & 74.48 & 62.80 \\
\hline 7 & 3 & - & 49.89 & 85.01 & 83.66 & 68.77 & 80.22 & 70.37 \\
\hline 8 & $31 / 2$ & - & - & 92.56 & 90.01 & 82.90 & 90.46 & 80.03 \\
\hline 9 & 4 & - & - & - & 99.48 & 91.66 & 98.25 & 92.89 \\
\hline
\end{tabular}

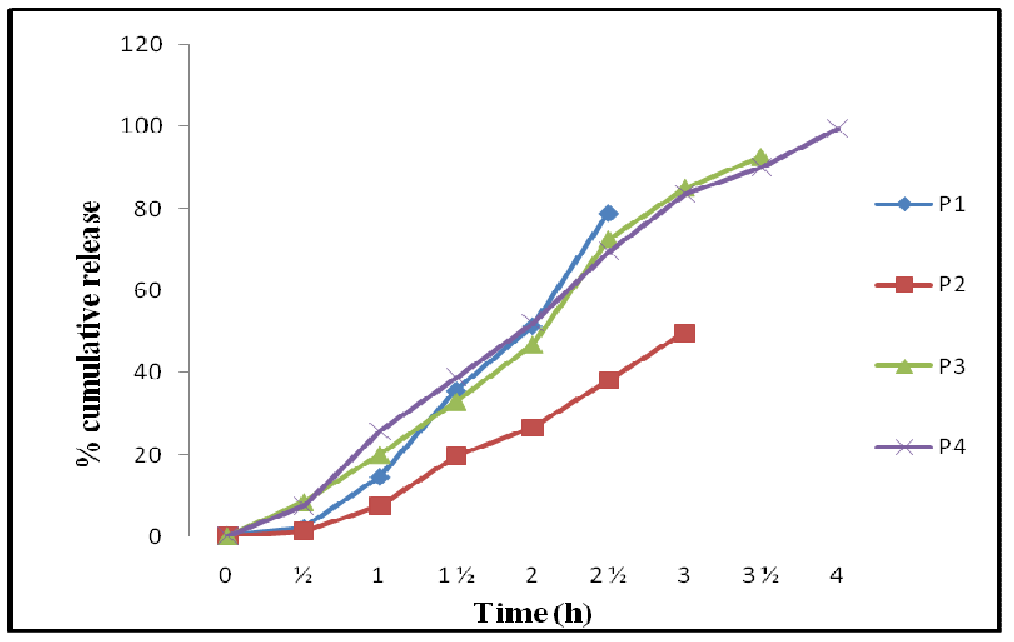

Fig. 10: Cumulative release of ciprofloxacin hydrochloride ocular insert containing natural polymer

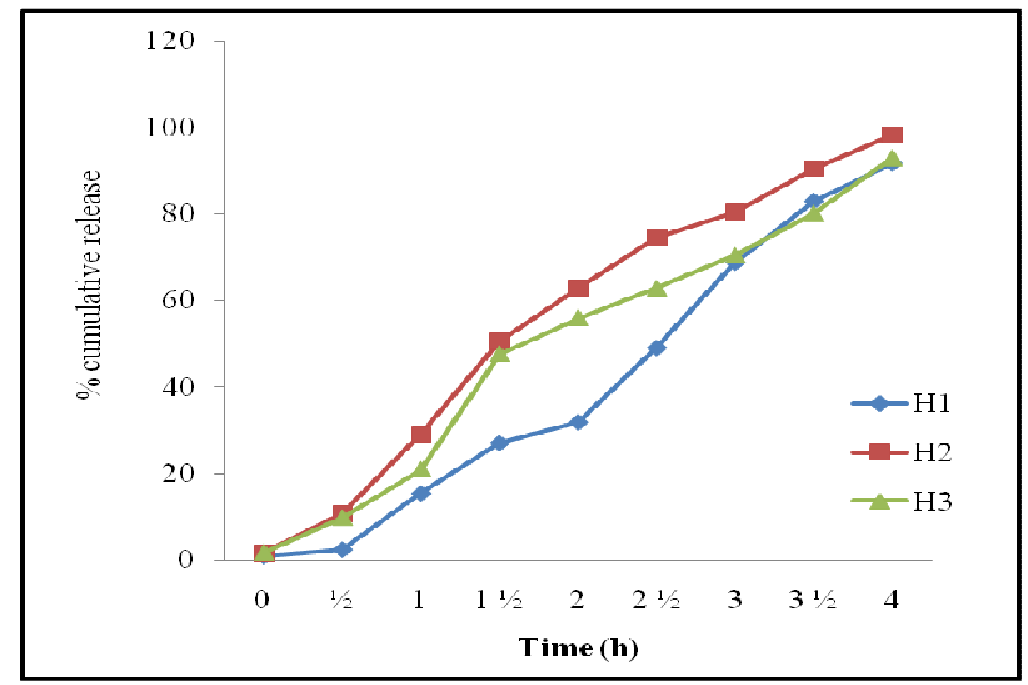

Fig. 11: Cumulative release of ciprofloxacin hydrochloride ocular insert containing HPMC

Table 9: Folding endurance and \% drug content of selected batches of ciprofloxacin hydrochloride ocular inserts

\begin{tabular}{llll}
\hline S. No. & Batch & Folding endurance & \% drug content \\
\hline 1 & H2 & 51.63 & 94.19 \\
2 & P3 & 60.23 & 91.38 \\
3 & P4 & 65.32 & 98.19 \\
\hline
\end{tabular}




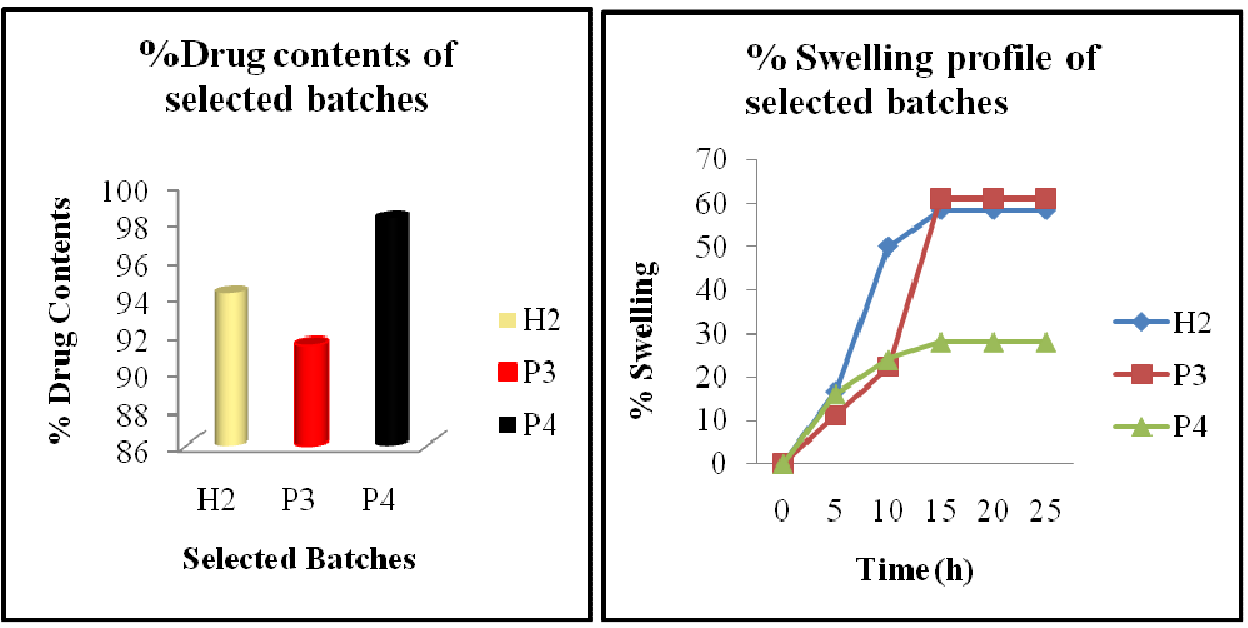

Fig. 12: Graphical representation of \% drug content and \%swelling profile of selected batches of ciprofloxacin hydrochloride ocular insert

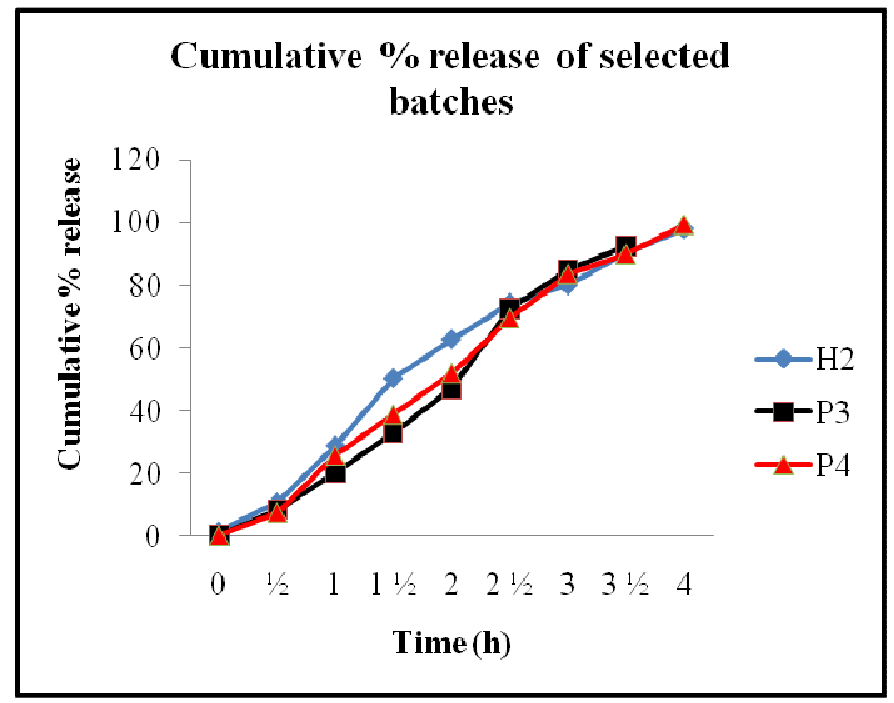

Fig. 13: Cumulative \% release of selected batches of ciprofloxacin hydrochloride ocular insert

Table 10: \% drug release of selected batch

\begin{tabular}{lllll}
\hline S. No. & Time $(\mathbf{h})$ & \multicolumn{2}{l}{ \% drug release of selected formulation } & P4 \\
\cline { 3 - 5 } & & H2 & P3 & 0.11 \\
\hline 1 & 0 & 1.56 & 0.17 & 7.52 \\
2 & 10.72 & 28.96 & 8.46 & 38.82 \\
3 & 1 & 50.49 & 20.02 & 52.03 \\
4 & $11 / 2$ & 62.92 & 32.94 & 69.55 \\
5 & 2 & 74.48 & 46.85 & 83.66 \\
6 & $21 / 2$ & 80.22 & 72.44 & 90.01 \\
7 & 3 & 90.46 & 95.01 & 99.48 \\
8 & $31 / 2$ & 98.25 & 92.56 & \\
9 & 4 & & & \\
\hline
\end{tabular}

On the basis of the above comparison studies formulation of P4 perform better as compare to all the selected formulation batches. The formulation p4 showing better release profile, drug content uniformity and acceptable swelling index high folding endurance batch P4 shows high folding endurance.

Table 11: Sterility test observation for bacteria

\begin{tabular}{|c|c|c|c|c|}
\hline \multirow[t]{2}{*}{ S. No. } & \multirow[t]{2}{*}{ Sample } & \multicolumn{3}{|c|}{ Time (h) } \\
\hline & & 12 & 24 & 36 \\
\hline 1 & Positive Control & + & + & + \\
\hline 2 & Negative Control & - & - & - \\
\hline 3 & Test & - & - & + \\
\hline
\end{tabular}




\section{Test for fungi}

In this study there was no sign of growth found in the 'test' Containing prepared ocular insert but 'negative control' tubes contain only SCDM, also shows some turbidity and minor growth of fungi and there was macroscopic evidence of microbial growth in 'positive control' tube. The results found that the prepared ocular insert $\mathrm{P} 4$ tested for fungal growths pass the test for sterility.

Table 12: Sterility test observation for fungi

\begin{tabular}{lllll}
\hline S. No. & Sample & Time (h) & \\
\cline { 3 - 5 } & & $\mathbf{1 2}$ & $\mathbf{2 4}$ & $\mathbf{3}$ \\
\hline 1 & Positive Control & $\mathbf{+}$ & + & + \\
2 & Negative Control & - & - & + \\
3 & Test & & + \\
\hline
\end{tabular}

\section{CONCLUSION}

The ocular inserts of ciprofloxacin hydrochloride were prepared using polymer Plantago ovata and HPMC by solvent casting method. Prepared inserts in the present study were semitransparent and the physicochemical properties of the insert are good. The mixing of the drug in to the polymer is uniform, Due to this uniformity; the drug content of all formulation is excellent. Formulation P4 was selected because it shows better release profile, drug content and other physicochemical properties than other prepared batches. All the prepared inserts showed drug in vitro drug release for the period of $4 \mathrm{~h}$. An in vitro drug release study revealed that ocular formulation formulations give a prolong action. It can be concluded that the formulations prepared by the natural polymer (Plantago ovata) containing ciprofloxacin hydrochloride was used as anti bacterial. The formulation is long acting,

Thus the data collectively support the hypothesis that ciprofloxacin hydrochloride ocular insert formulation is promising delivery systems to enhance the drug release of ciprofloxacin hydrochloride

\section{AUTHORS CONTRIBUTIONS}

All the author have contributed equally

\section{CONFLICT OF INTERESTS}

\section{Declared none}

\section{REFERENCES}

1. Bruck Sd. Controlled drug delivery. Bocaraton, Florida: Crc Press; 1983.

2. Baeyens V, O Felt-Baeyens, S Rougier, S Pheulpin, B Boisrame, R Gurny. Clinical evaluation of bioadhesive ophthalmic drug inserts $\left(\right.$ Bodi $\left.{ }^{\circledR}\right)$ for the treatment of external ocular infections in dogs. J Controlled Release 2002;85:163-8.

3. Patel A, Cholkar K, Agrahari V, Mitra AK. Ocular drug delivery systems: an overview. World J Pharmacol 2013;2:47-64.

4. Bower KS, RP Kowalski, YJ Gordon. Fluoroquinolones in the treatment of bacterial keratitis. Am J Ophthalmol 1996;121:712.

5. Shanmugam S, Manavalan R, Venkappayya D, Sundaramoorthy $\mathrm{K}$, Mounnissamy V M, Hemalatha, et al. Natural polymers and thire application. Indian J Nat Prod Resour 2005;4:478-81.

6. Abadia AR, Aramayona JJ, Munoz MJ. Ciprofloxacin pharmacokinetics in dogs following oral administration. Zentralbl Veterinarmed A 1995;42:505-11.

7. Kulkarni GT, Gowthamarajan K, Rao BG, Suresh B. Evaluation of binding properties of Plantago Ovata and Gonella Foenumgraecum mucilage. Indian Drugs 2002;39:422-5.

8. Kulkarni GT, Gowthamarajan K, Rao BG, Suresh B. Evaluation of binding properties of selected natural mucilage. J Sci Industrial Res 2002;61:529-32.

9. Tahir MA, Awadhesh K, Swati S, Sant S, Sajid MA, Pattnaik GD, et al. Optimization of fast disintegrating tablets for diclofenac sodium using isabgol mucilage as super disintegrant. Int J Pharm Sci 2010;2:496-501.
10. Mehta DM, Shelat PK, Parejiya PB, Patel AJ, Barot B. Investigation of Plantago Ovata husk as a disintragation agent for development of famotidin tablets. Int J Pharm Sci Nanotechnol 2011;4:1412-7.

11. Http://Www.Ijpcbs.Com/Files/08-209.Pdf. [Last accessed on 10 Mar 2018]

12. Sucheta B, Jarande K, Patil M, Patanakar RD. Isolation and evaluation of natural superdisintegrant from Plantago Ovata in mdts of telmisartan. J Pharm Cosmetol 2012;2:9-21.

13. Safila Naveed. Simple UV spectrophotometric assay of atorvastatin API formulation and their comparative study. Global J Med Res 2014;14:35-8.

14. Malviya R. Extraction characterization and evaluation of selected mucilage as pharmaceutical excipient. Pharm Excipient 2011;41:39-44.

15. Gevariya $\mathrm{H}$, Patel JK. Long acting betaxolol ocular inserts based on polymer composite. Curr Drug Delivery 2013;10:1-10.

16. http://Www.Chem.Ucalgary.Ca/Courses/351/laboratory/Melt ingpoint.Pdf. [Last accessed on 10 Mar 2018]

17. Ghelani TK, Seth AK, Saini V, Singhal S, Kumar S, Yadav YC. Formulation and evaluation of timolol maleate ocular insert. Asian J Biochem 2011;1:166-74.

18. Manjunatha KM, Kulkarni GT. Design, development and evaluation of controlled release levobunolol hydrochloride ocular inserts for glaucoma therapy. J Chronother Drug Delivery 2012;3:87-97.

19. Aburahma MH, Mahmoud A. Biodegradable ocular inserts for sustained delivery of brimonidine tartarate: preparation and in vitro/in vivo evaluation. Am Assoc Pharm Sci Technol 2011;12:1335-47.

20. Shivhare UD, Chavan MA, Bhusari KP, Mathur VB, Kakade VN. Formulation development and evaluation of controlled release ocular insert. Int J Biol Pharm Res 2012;3:66-74.

21. Manjunatha KN, Kulkarni GT, Ismail Md. Design and optimization of controlled release ocular inserts of dorzolamide hydrochloride and timolol maleate for treatment of glaucoma. Int General Pharm Sci Res 2012;3:3915-22.

22. Aher ND. Nair HA. Bilayered films based on novel polymer derivative for improved ocular therapy of gatifloxacin. Sci World J 2014:1-9. http://dx.doi.org/10.1155/2014/297603

23. Singh V, Bushetti SS, Appala R, Ahmed R, Singh M, Ajmal M. Polymeric ocular hydrogels and ophthalmic inserts for controlled release of timolol maleate. J Pharm Bioallied Sci 2011;3:1/9-9/9.

24. Sachdeva D, Bhandari A. Design, formulation, evaluation of levobunolol hcl ocular inserts. J Pharm Sci Res 2011;3:1625-31.

25. Gevariya H, Patel JK. Long acting betaxolol ocular inserts based on polymer composite. Curr Drug Delivery 2013;10:1-10.

26. Nair RV, Nair SC, Anoop KR. Ocular insert of timolol maleate using naturally occurring biodegradable polymer. J Chem Pharm Res 2015;7:476-85.

27. Indian Pharmacopoeia 2010. New Delhi: Indian Pharmacopoeia Commission, Ministry of Health and Family Welfare, Govt. of India; 2007. p. 52-9.

28. Khokhar P. Design and characterisation of chloramphenicol ocular insert for ocular drugdelivery. Int J Pharma Res Rev 2015;4:9-15. 